\title{
Las Obras completas de Pedro Henríquez Ureña
}

Desde 2015, cuando el Ministerio de Cultura de la República Dominicana publicó los últimos siete tomos de los catorce que comprenden la más reciente iniciativa de recopilación de las Obras completas de Pedro Henríquez Ureña, los estudiosos del legado del maestro dominicano cuentan con una herramienta de trabajo cuidada con esmerado rigor por Miguel D. Mena.

La labor de Mena ha sido verdaderamente hercúlea. Invirtió largos años de trabajo de sabueso literario escarbando en bibliotecas de todo el continente, contactando a los discípulos del maestro, trabajando mano a mano con doña Sonia Henríquez en el inventario de todo lo que su padre había dejado a su muerte y revisando con lupa las tres cajas de documentos del Archivo Pedro Henríquez Ureña en El Colegio de México.

El camino abierto por Juan Jacobo de Lara en 1976, con el primer intento de recoger toda la obra de Henríquez Ureña, apenas marcó un empeño que la iniciativa de 2003 por parte de la Secretaría de Estado de Cultura no pudo mejorar. La de Mena es ciertamente la más exhaustiva tarea de recopilación. A esto hay que agregar su encomiable labor en cuanto al establecimiento de los textos. En efecto, Mena no sólo reunió todo lo conocido del maestro, sino que cotejó línea por línea las diferentes versiones de los textos que Henríquez Ureña había dado a la imprenta. Las variantes que el gran humanista introdujo en sus escritos fueron recurrentes; Mena las identifica todas, incluso las que Henríquez Ureña realizó de su puño y letra en los manuscritos que se conservan en El Colegio de México. Se trata de un recurso invaluable tanto para el especialista como para el lector curioso por conocer la manera en que funcionaba el taller del filólogo. 
Entre los aspectos más notables de estas Obras completas hay que subrayar la inclusión de En la orilla: gustos y colores, uno de los numerosos hallazgos de Mena al examinar el archivo personal de Pedro Henríquez Ureña. De esta curiosa colección de textos del dominicano, en su mayoría en clave aforística, se tenía noticias por las menciones en su epistolario y la publicación de algunos fragmentos en la compilación de Lara. Mena rastrea estos detalles al tiempo que señala las partes del libro que nunca llegaron a imprenta.

Otros aportes importantes por su rareza y valor bibliográfico son el hallazgo de una conferencia sobre Gilbert Keith Chesterton de 1936, la recopilación de todas las colaboraciones de Henríquez Ureña en la revista Sur, así como múltiples declaraciones y textos de saludo, homenaje y agradecimiento hallados en el archivo personal del maestro.

A pesar de la importancia de la aparición de las Obras completas de Pedro Henríquez Ureña, este acontecimiento no ha sido saludado por ninguno de los especialistas dominicanos; es más, los comentaristas actuales de la obra del gran humanista en su país de origen ni siquiera citan a partir de este archivo, sino que recurren a lo recogido por Juan Jacobo de Lara en los años setenta. En un momento en que los estudios en torno al sabio dominicano, tan caro a la historia intelectual del México moderno, demuestran un renovado interés en su legado, justo es celebrar el resultado de un esfuerzo como el de Miguel D. Mena.

El legado de Pedro Henríquez Ureña está aún lejos de poder considerarse identificado a cabalidad. Hay todavía considerables lagunas, sobre todo en lo tocante a su epistolario de los años argentinos, que sólo podrán cubrirse cuando ciertos potentados del mundo intelectual dominicano empiecen a mostrar magnanimidad compartiendo los tesoros que esconden en sus bibliotecas.

NÉSTOR E. RODRÍGUEZ 